\title{
TEACHERS DIFFICULTIES AND STRUGGLES IN MODULAR DISTANCE LEARNING DELIVERY: INPUT TO BE-LCP
}

\author{
Lordian V. De Leon \\ Faculty, Calminue Integrated National High School
}

Article DOI: https://doi.org/10.36713/epra7901

DOI No: 10.36713/epra7901

\begin{abstract}
The purpose of this study was to determine the level of Teachers Difficulties and Struggles in Modular Distance Learning Delivery: Input to BE-LCP. The information on related literature and studies were gathered to formulate the hyphothesis, conceptual framework presented in the paradigm and the definitions of terms. Specifically, the information was found in journals documents, published and unpublished materials like thesis, readings and internet.

Descriptive method was used to determine the answers from the questions stated above. The respondents of this study were sixty public junior and senior high school teachers in Cavinti, Laguna. The study used questionnaire checklist by means of google form as the main tool in gathering the data. The formulation of the questionnaire was based on the investigations and findings of other researchers discussed in the related literatures and studies. The main instrument used in gathering data was the questionnaire checklist was the statistical tool such as Mean and Standard Deviation.

From the data gathered and discussed, the following conclusions were derived: The computed mean value registered Teachers Difficulties and Struggles in Modular Distance Learning Delivery: Input to BE-LCP in terms of Strategy is Highly Practiced shows that it is being practiced. At the time of pandemic in the learning continuity, teachers and parents encourage learners in the new normal. Understanding the current education setup can make a way to guide the learners in answering their activities. By giving ample time and don't give pressure can help learners to answer their task. But teachers must explain or give clear instruction for learners to easily understand the lesson. In this time of pandemic, school must open their communication to the stakeholders as they are the one who can help in the learning continuity. As they will work as one for the sake of the learners' progress as they need the support to cope up with the current situation.
\end{abstract}

KEYWORDS: Modular Distance Learning, Learning Continuity, Instruction, Stakeholders, Learning Outcomes, Learning Plan

\section{INTRODUCTION}

As the world grows into technologically sophisticated, there is a great demand for the hottest electronic gadgets. Cellphone, laptop and any type of electronic gadgets that supports services like text messaging, email, internet and internet access. When the COVID-19 outbreak starts, it caused major disruptions on individuals' out-of-home activities, wherein Philippines is one of the countries that has been affected an placed cities under lockdown which orders schools to suspends classes in all levels avoiding the face to face interaction.

The global outbreak of the highly contagious new strain of coronavirus known as COVID-19, for which there is yet no vaccine, continues to pose unprecedented challenges. At this point, the biggest impact of COVID-19 arises from the need to practice stringent social or physical distancing to prevent or mitigate its spread. For the Department of Education (DepEd), this meant the cancellation of classes and other school activities for the remaining weeks of SY 2019-2020, and that for SY 2020-2021, schools must find ways for 


\section{EPRA International Journal of Research and Development (IJRD)

\author{
Volume: 6 | Issue: 7 | July 2021 \\ - Peer Reviewed Journal
}

learning to continue amidst the threat and uncertainties brought about by COVID-19, while ensuring the health, safety, and well-being of all learners, teachers, and personnel of the Department.

The continuity of education after the current crisis is a major national concern. Billions of children and youth were affected by the school closures across the world due to the global outbreak of Covid-19. Since there is no face to face interaction, it all boils down to online learning on education. But not all of the people has an access to technology.

The purpose of this study is to focus on teachers' difficulties and struggles in modular distance learning delivery: input to BE-LCP. The main challenge most specially to all teachers are the interventions or actions for us to be able to give alternative solutions to this crisis. And also there are many teaching strategies as well as information regarding what a classroom that values social interaction, authentic problem solving, and personal reflection looks like highlighted in this study. It is the author's hope that the research cited and philosophies focused on lead readers to see the immense value of engaged learning in students' development and success in school, as well as throughout the rest of their lives.

\section{OBJECTIVE OF THE STUDY}

The main purpose of the study is was to investigate the teachers difficulties and struggles in Modular Distance Learning Delivery: Input to BE-LCP Precisely, the study pursued to answer the following questions:

1. What is the level of teachers' difficulties and struggles in modular distance learning delivery: input to BE-LCP in terms of:

1.1 Strategy

1.2 Learning Plan

1.3 Stakeholders Involvement

2. What is the status of BE-LCP Intervention program in terms of:

2.1 Learning Outcomes

2.2 Modular Learning Task

2.3 Compliance

2.4 Participation

3. Is there a significant relationship between the level of teachers' difficulties and struggles in modular distance learning delivery: input to BE-LCP to the status of BE-LCP Intervention program?

\section{METHODOLOGY}

The Descriptive method on used to determine the answers to the questions stated above. The respondents of this study were sixty public junior and senior high school teachers in Cavinti, Laguna. The study used a questionnaire checklist by means of google form as the main tool in gathering the data. The formulation of the questionnaire was based on the investigations and findings of other researchers discussed in the related literature and studies. The main instrument used in gathering data was a questionnaire checklist and the statistical tools utilized were as Mean and Standard Deviation.

This study utilized in selected respondents of teachers difficulties and struggles in modular distance learning delivery purposive sampling as they were only thirty (60) who will answer the questionnaire. The researcher believed these respondents were the right persons to give the needed information.

The first thing done by the research was to make a questionnaire in order to find out the level of teachers difficulties and struggles in modular distance learning delivery. The respondents were composed of selected sixty (60) respondents. Then a letter of request addressed from the Schools Division Superintendent and Principal of Secondary in Cavinti for the researcher to conduct an actual gathering of data from the said respondents.

\section{RELATED LITERATURE}

Based on the result of the research conducted by Carreon (2018) it shows that the teachers who always prepared and utilized any available technology resources, create a tool in assessing learning and making the environment more engaging will be as an intervention for student outcomes can depends on the efficiency and effectiveness of implementation of the teachers.

Since on the current situation it has been a challenging journey for all of the people especially to education sector. There are some instances that the learners can learn on their own but the most important thing is the intervention.

Learning outcomes are defined as 'statements of what a learner knows, understands and is able to do after completion of learning' (Cedefop, 2009 as cited by Harris \& Clayton 2019). It is basically what the learners developed throughout the subject matter. 
Modular learning is the most popular type of Distance Learning. In the Philippines, this learning modality is currently used by all public schools. Based on the survey conducted by the Department of Education (DepEd), learning through printed and digital modules emerged as the preferred learning modality who enrolled this academic year due to some instance and to those learners who is in the rural areas who cannot access to online learning.

The use of modules encourages independent study. One of the benefits of using modules for instruction is the acquisition of better self-study or learning skills among the learners. They develop a sense of responsibility in accomplishing the tasks provided in the module. By the use of the modules they are learning how to learn (Nardo, M.T.B, 2017).

Participation and engagement predict students' achievement and comprehension of educational material (Linnenbrink \& Pintrich, 2003 as cited by Onge \& Eitel 2017). Teachers can foster greater student participation and engagement by paying particular attention to their classroom arrangement. But as of the moment, teachers are trying their best to make the learners and parents participate in new normal at the time of pandemic with the availability of the learning delivery modality.

Finally, grading class participation shows to the student what kind of learning and thinking is valued by the teachers.(Bean \& Peterson, 1998 as cited by Yu, 2018). As in the Philippines mostly is using the Modular Approach, it can be monitored and evaluate through the learners output.

\section{RESULTS AND DISCUSSION}

Teachers' difficulties and struggles in Modular Distance Learning Delivery: Input to BE-LCP

The intervention practices of Public School Teachers in Cavinti, Laguna is described in terms of strategy, learning plan and stakeholders involvement as shown in table 1, table 2 and table 3 . Table 1 presents the Teachers' difficulties and struggles in Modular Distance Learning Delivery: Input to BE-LCP in terms of Strategy with the overall mean of 4.21 with verbal interpretation of Highly Practiced.

Table 1. Teachers' difficulties and struggles in modular distance learning delivery: input to BE-LCP in terms of Strategy

\begin{tabular}{|c|c|c|c|}
\hline Indicators & Mean & S.D. & $\begin{array}{l}\text { Verbal } \\
\text { Interpretation }\end{array}$ \\
\hline 1. Allows students to do in-depth understanding of the lesson & 4.08 & 0.869 & Practiced \\
\hline 2. Sets students' minds to do specific process or activities. & 4.10 & 0.915 & Practiced \\
\hline 3. Provides a way to help students express their feelings. & 4.20 & 0.917 & Highly practiced \\
\hline 4. Encourage/ motivating learners in the new normal. & 4.35 & 1.005 & Highly practiced \\
\hline $\begin{array}{l}\text { 5. Attending webinars that can be applied in the new normal setup } \\
\text { of education. }\end{array}$ & 4.30 & 1.013 & Highly practiced \\
\hline Overall Mean & \multicolumn{3}{|c|}{ Highly Practiced } \\
\hline
\end{tabular}

Legend:

$\begin{array}{cc}4.20-5.00 & \text { Highly Practiced } \\ 3.40-4.19 & \text { Practiced } \\ 2.60-3.39 & \text { Moderately Practiced } \\ 1.80-2.59 & \text { Rarely Practiced } \\ 1.00-1.79 & \text { Not at all Practiced }\end{array}$

Among the strategies highly practiced by the teachers include attendance to webinars that can be applied in the new normal setup of education $(M=4.30, S D=1.013)$, motivating learners $(M=4.35, S D=1.005)$, and providing students opportunities to express themselves $(M=4.20, S D=0.917)$. The teachers also practiced the strategies like allowing students to do in-depth understanding of the lesson $(M=4.08, S D=0.869)$ and setting up the students' minds to do specific process or activities $(M=4.10, S D=0.915)$. This means that teachers all over the country accepted the challenge in terms of teaching from traditional teaching to new normal. Many of the teachers find ways to navigate new technique and to be equipped to give quality education to their learners. The lack of internet connections does not hinder teachers' enthusiasm for learning the new approach. (Tupas \& Linas-Laguda 2020) The overall mean of 4.21 indicates that the teacher highly practiced strategies that would improve their pedagogy and consequently the students' participation and performance. This means that using interventions in the time of pandemic is very essential to the learning continuity of the students.

Table 2 presents the Teachers' difficulties and struggles in Modular Distance Learning Delivery: Input to BE-LCP in terms of Learning Plan with the overall mean of 4.20 with verbal interpretation of Highly Practiced. 


\section{EPRA International Journal of Research and Development (IJRD)

\author{
Volume: 6 | Issue: 7 | July $2021 \quad$ - Peer Reviewed Journal
}

Table 2. Teachers' difficulties and struggles in modular distance learning delivery: input to BE-LCP in terms of Learning Plan

\begin{tabular}{|c|c|c|c|c|}
\hline & Indicators & Mean & S.D. & $\begin{array}{l}\text { Verbal } \\
\text { Interpretation }\end{array}$ \\
\hline 1. & Explaining objectives of lessons clearly. & 4.18 & 0.930 & Practiced \\
\hline 2. & Explains the topic for the learners to understand. & 4.22 & 0.993 & Highly practiced \\
\hline & $\begin{array}{l}\text { Provides examples and further explanations in a way the } \\
\text { students understand the lesson. }\end{array}$ & 4.20 & 0.971 & Highly practiced \\
\hline 4. & Give the students ample time to process the lesson. & 4.20 & 1.022 & Highly practiced \\
\hline & $\begin{array}{l}\text { Monitor progress of learning based from the output submitted } \\
\text { by the students with rubrics. }\end{array}$ & 4.18 & 0.948 & Practiced \\
\hline \multicolumn{2}{|c|}{ Overall Mean } & \multicolumn{3}{|c|}{ Highly Practiced } \\
\hline
\end{tabular}

Legend:

$4.20-5.00 \quad$ Highly Practiced

$3.40-4.19$ Practiced

$2.60-3.39$ Moderately Practiced

$1.80-2.59 \quad$ Rarely Practiced

$1.00-1.79 \quad$ Not at all Practiced

Among the strategies highly practiced by the teachers includes giving ample time to process the lesson $(M=4.20, S D=1.022)$, provides examples and further explanations in a way the students understand the lesson $(M=4.20, S D=1.022)$, and explains the topic for the learners to understand. $(M=4.22, S D=0.993)$. The teachers also practiced the strategies like monitoring the progress of learning based from the output submitted by the students with rubrics $(M=4.18, S D=0.948)$ and explaining objectives of lessons clearly. $(M=4.18$, $S D=0.930$ ). The overall mean of 4.20 indicates that the teacher highly practiced strategies that would improve their pedagogy and consequently the students' participation and performance. This means that using interventions in the time of pandemic is very essential to the learning continuity of the students.

Table 3 presents the Teachers' difficulties and struggles in Modular Distance Learning Delivery: Input to BE-LCP in terms of Stakeholders Involvement with the overall mean of 4.15 with verbal interpretation of Practiced.

Table 3. Teachers' difficulties and struggles in modular distance learning delivery: input to BE-LCP in terms of Stakeholders' Involvement

\begin{tabular}{|l|l|l|l|}
\hline Indicators & Mean & S.D. & $\begin{array}{l}\text { Verbal } \\
\text { Interpretation }\end{array}$ \\
\hline $\begin{array}{l}\text { The school has an open line communication with its } \\
\text { stakeholders. }\end{array}$ & 4.10 & 1.037 & Practiced \\
\hline $\begin{array}{l}\text { Schools are transparent to the stakeholders in terms of students' } \\
\text { progress. }\end{array}$ & 4.15 & 0.936 & Practiced \\
\hline $\begin{array}{l}\text { The school and community work as partners for the learner's } \\
\text { development during the pandemic. }\end{array}$ & 4.12 & 0.940 & Practiced \\
\hline $\begin{array}{l}\text { Allow the parents to know if their child needs guidance or help } \\
\text { academically. }\end{array}$ & 4.20 & 0.988 & Highly practiced \\
\hline $\begin{array}{l}\text { Encourage the parents to support their child to feel confident in } \\
\text { his or her learning. }\end{array}$ & 4.18 & 1.017 & Practiced \\
\hline Overall Mean & $\mathbf{4 . 1 5}$ & Practiced \\
\hline
\end{tabular}

Legend:

$\begin{array}{cc}4.20-5.00 & \text { Highly Practiced } \\ 3.40-4.19 & \text { Practiced } \\ 2.60-3.39 & \text { Moderately Practiced } \\ 1.80-2.59 & \text { Rarely Practiced } \\ 1.00-1.79 & \text { Not at all Practiced }\end{array}$

Among the strategies highly practiced by the teachers includes allowing the parents to know if their child needs guidance or help academically. $(M=4.20, S D=0.988)$. The teachers also practiced the strategies like 


\section{EPRA International Journal of Research and Development (IJRD)

\author{
Volume: 6 | Issue: 7 | July $2021 \quad$ - Peer Reviewed Journal
}

The school has an open line communication with its stakeholders $(M=4.10, S D=1.037)$, encourage the parents to support their child to feel confident in his or her learning $(M=4.18, S D=1.017)$, the school and community work as partners for the learner's development during the pandemic $(M=4.12, S D=0.940)$ and schools are transparent to the stakeholders in terms of students' progress $(M=4.15, S D=0.936)$.

\section{Status of BE-LCP Intervention program}

The Status of BE-LCP Intervention program in Cavinti, Laguna is described in terms of learning outcomes, modular learning task, compliance and participation.

Table 4 presents the status of the BE-LCP Intervention Program in terms of Learning Outcomes with the overall mean of 3.77 with verbal interpretation of High.

Table 4. Status of the BE-LCP Intervention Program in terms of Learning Outcomes

\begin{tabular}{|l|l|l|l|}
\hline \multicolumn{1}{|c|}{ Indicators } & Mean & S.D. & $\begin{array}{l}\text { Verbal } \\
\text { Interpretation }\end{array}$ \\
\hline The students experience difficulties in learning. & 3.95 & 0.999 & High \\
\hline The students get lowest scores in the learning activities. & 3.58 & 0.889 & High \\
\hline The students get bored while answering the activities. & 3.77 & 0.998 & High \\
\hline Limited time to answer affects the students' outcome performance. & 3.77 & 1.079 & High \\
\hline $\begin{array}{l}\text { Some students were not able to pass their output and get new answer } \\
\text { sheet. }\end{array}$ & 3.80 & 1.054 & High \\
\hline Overall Mean & $\mathbf{3 . 7 7}$ & \multicolumn{2}{|c|}{ High } \\
\hline
\end{tabular}

Legend:

$4.20-5.00 \quad$ Very High

$3.40-4.19$ High

2.60-3.39 Moderately High

$1.80-2.59$ Low

$1.00-1.79$ Very Low

Among the status of the BE-LCP Intervention Program in terms of Learning Outcomes with high by includes limited time to answer affects the students' outcome performance $(\mathrm{M}=3.77, \mathrm{SD}=1.079)$, some students were not able to pass their output and get new answer sheet $(\mathrm{M}=3.80, \mathrm{SD}=1.054)$, students experience difficulties in learning $(\mathrm{M}=3.95, \mathrm{SD}=0.999)$, students gets bored while answering the activities $(\mathrm{M}=3.77$, $\mathrm{SD}=0.998)$ and the students get lowest scores in the learning activities $(\mathrm{M}=3.58, \mathrm{SD}=0.889)$ The overall mean of 3.77 indicates that the level of students' outcomes without intervention is high that would needs improvement to the consequently the students' participation and performance. This means that using interventions in the time of pandemic is very essential to the learning continuity of the students.

Table 5 presents the Status of the BE-LCP Intervention Program in terms of Modular Learning Task with the overall mean of 4.12 with verbal interpretation of High.

Table 5. Status of the BE-LCP Intervention Program in terms of Modular Learning Task

\begin{tabular}{|c|c|c|c|}
\hline Indicators & Mean & S.D. & $\begin{array}{l}\text { Verbal } \\
\text { Interpretation }\end{array}$ \\
\hline $\begin{array}{l}\text { 1. Answer sheet were provided to facilitate answering and } \\
\text { checking of learning task. }\end{array}$ & 4.13 & 1.016 & High \\
\hline $\begin{array}{l}\text { 2. Monitoring of students regarding their progress in answering } \\
\text { learning tasks. }\end{array}$ & 4.18 & 1.066 & High \\
\hline $\begin{array}{l}\text { 3. Giving self - made activities which is based on the learning } \\
\text { plan. }\end{array}$ & 4.12 & 0.993 & High \\
\hline $\begin{array}{l}\text { 4. Giving ample time to answer the learning activities to avoid } \\
\text { pressure. }\end{array}$ & 4.20 & 1.005 & Very high \\
\hline 5. Increase in the number of students who passed their output. & 3.98 & 1.049 & High \\
\hline Overall Mean & \multicolumn{3}{|c|}{ High } \\
\hline
\end{tabular}




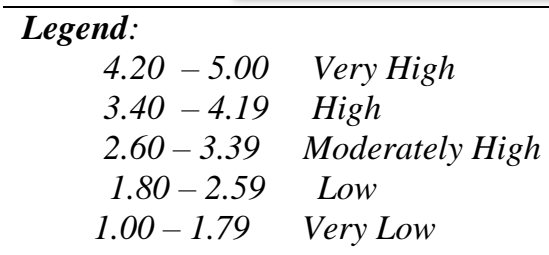

Among the status of the BE-LCP Intervention Program in terms of Modular Learning Task with high by includes limited time to answer affects the students' outcome performance $(M=3.77, S D=1.079)$, some students were not able to pass their output and get new answer sheet $(M=3.80, S D=1.054)$, students experience difficulties in learning $(M=3.95, S D=0.999)$, students gets bored while answering the activities $(M=3.77$, $S D=0.998)$ and the students get lowest scores in the learning activities $(M=3.58, S D=0.889)$. The overall mean of 4.12 indicates that the status of the BE-LCP Intervention Program in terms of Modular Learning Task is high that would needs improvement to the consequently the students' participation and performance. This means that using interventions in the time of pandemic is very essential to the learning continuity of the students.

Table 6 presents the Status of the BE-LCP Intervention Program in terms of Compliance with the overall mean of 3.92 with verbal interpretation of High.

Table 6. Status of BE-LCP Intervention program in terms of Compliance

\begin{tabular}{|c|c|c|c|}
\hline Indicators & Mean & S.D. & $\begin{array}{l}\text { Verbal } \\
\text { Interpretation }\end{array}$ \\
\hline $\begin{array}{l}\text { The parents follow the protocol when it comes to the submission of } \\
\text { the outputs of the learners. }\end{array}$ & 4.10 & 0.915 & High \\
\hline Follow the necessary instruction given by the teachers. & 4.13 & 0.791 & High \\
\hline Submits the output at the given schedule. & 3.48 & 1.017 & High \\
\hline $\begin{array}{l}\text { Learners completes the necessary requirement on the specific } \\
\text { learning task. }\end{array}$ & 3.47 & 0.965 & High \\
\hline The teacher checks if the learners submit their output. & 4.42 & 0.926 & Very High \\
\hline Overall Mean & 3.92 & $\mathrm{Hi}_{\mathrm{z}}$ & \\
\hline \multicolumn{4}{|l|}{ Legend: } \\
\hline \multicolumn{4}{|l|}{ Very High } \\
\hline \multicolumn{4}{|l|}{ High } \\
\hline \multicolumn{4}{|l|}{ Moderately High } \\
\hline \multicolumn{4}{|l|}{ Low } \\
\hline \multicolumn{4}{|l|}{ Very Low } \\
\hline
\end{tabular}

Among the status of the BE-LCP Intervention Program in terms of Compliance with high by includes the teacher checks if the learners submit their output. $(M=4.42, S D=0.926)$, follow the necessary instruction given by the teachers $(M=3.13, S D=0.791)$, the parents follow the protocol when it comes to the submission of the outputs of the learners $(M=4.10, S D=0.915)$, Learners completes the necessary requirement on the specific learning task $(M=3.47, S D=0.965)$ and submits the output at the given schedule. $(M=3.48, S D=1.017)$. The overall mean of 3.92 indicates that the status of the BE-LCP Intervention Program in terms of Compliance is high that would needs improvement to the consequently the compliance of students' This means that using interventions in the time of pandemic is very essential to the learning continuity of the students.

Table 7 presents the Status of the BE-LCP Intervention Program in terms of Participation with the overall mean of 4.01 with verbal interpretation of High. 


\section{EPRA International Journal of Research and Development (IJRD)

\author{
Volume: 6 | Issue: 7 | July $2021 \quad$ - Peer Reviewed Journal
}

Table 7 Status of BE-LCP Intervention program in terms of Participation

\begin{tabular}{|c|c|c|c|}
\hline Indicators & Mean & S.D. & $\begin{array}{c}\text { Verbal } \\
\text { Interpretation }\end{array}$ \\
\hline Parents submits the outputs of the learner at the time of pandemic. & 3.92 & 0.850 & High \\
\hline Parents participates in the guidance of the learners. & 3.88 & 0.992 & High \\
\hline Maintains the actively participation of the parents on the BE-LCP. & 3.85 & 0.936 & High \\
\hline $\begin{array}{l}\text { Continuous communication of teacher and parents in monitoring the } \\
\text { learning progress of the learners. }\end{array}$ & 4.15 & 0.936 & High \\
\hline $\begin{array}{l}\text { The cooperation and support coming from parents will be very } \\
\text { important as the entire basic education system braces for the so-called } \\
\text { "new normal. }\end{array}$ & 4.23 & 0.981 & Very High \\
\hline Overall Mean & \multicolumn{3}{|c|}{$4.01 \quad$ High } \\
\hline $\begin{array}{cl}\text { Legend: } & \\
4.20-5.00 & \text { Very High } \\
3.40-4.19 & \text { High } \\
2.60-3.39 & \text { Moderately High } \\
1.80-2.59 & \text { Low } \\
1.00-1.79 & \text { Very Low }\end{array}$ & & & \\
\hline
\end{tabular}

Among the status of the BE-LCP Intervention Program in terms of Compliance with high by includes the teacher checks if the learners submit their output. $(M=4.42, S D=0.926)$, follow the necessary instruction given by the teachers $(M=3.13, S D=0.791)$, the parents follow the protocol when it comes to the submission of the outputs of the learners $(M=4.10, S D=0.915)$, Learners completes the necessary requirement on the specific learning task $(M=3.47, S D=0.965)$ and submits the output at the given schedule. $(M=3.48, S D=1.017)$. The overall mean of 4.01 indicates that the status of the BE-LCP Intervention Program in terms of Participation is high that would needs improvement to the consequently the compliance of students' This means that using interventions in the time of pandemic is very essential to the learning continuity of the students.

Table 8 presents the Significant relationship between the level of teachers' difficulties and struggles in modular distance learning delivery: input to BE-LCP to and status of BE-LCP Intervention program.

Table 8 Significant relationship between the level of teachers' difficulties and struggles in modular distance learning delivery: input to BE-LCP to and status of BE-LCP Intervention program

\begin{tabular}{|l|l|c|c|c|c|}
\hline Variables & $\begin{array}{c}\text { r- } \\
\text { value }\end{array}$ & p-value & $\begin{array}{c}\text { Degree of } \\
\text { Correlation }\end{array}$ & Analysis \\
\hline \multirow{4}{*}{ Strategy } & Learning Outcomes & 0.769 & 0.000 & High & Significant \\
\cline { 2 - 6 } & Modular Learning Task & 0.885 & 0.000 & Very High & Significant \\
\cline { 2 - 6 } & Compliance & -0.030 & 0.817 & Negligible & Not Significant \\
\cline { 2 - 6 } & Participation & 0.100 & 0.445 & Negligible & Not Significant \\
\hline \multirow{5}{*}{ Learning Plan } & Learning Outcomes & 0.714 & 0.000 & High & Significant \\
\cline { 2 - 6 } & Modular Learning Task & 0.817 & 0.000 & Very High & Significant \\
\cline { 2 - 6 } & Compliance & -0.097 & 0.462 & Negligible & Not Significant \\
\cline { 2 - 6 } & Participation & 0.021 & 0.872 & Negligible & Not Significant \\
\hline \multirow{3}{*}{ Stakeholder's } & Learning Outcomes & 0.715 & 0.000 & High & Significant \\
\cline { 2 - 6 } & Modular Learning Task & 0.799 & 0.000 & High & Significant \\
\cline { 2 - 6 } & Compliance & -0.068 & 0.607 & Negligible & Not Significant \\
\cline { 2 - 6 } & Participation & 0.076 & 0.564 & Negligible & Not Significant \\
\hline
\end{tabular}

$\begin{array}{ll}\text { *Significant at .05 level of significanc } \\ \begin{array}{l}\text { Legend } \\ \text { R-Values }\end{array} \\ \pm 0.81-1.00 & \text { Degree of Correlation } \\ \pm 0.51-0.80 & \text { very high correlation } \\ \pm 0.41-0.50 & \text { high correlation } \\ \pm 0.21-0.40 & \text { substantial correlation } \\ \pm 0.00-0.20 & \text { low correlation }\end{array}$




\section{EPRA International Journal of Research and Development (IJRD)

The relationship between the level of teachers' difficulties and struggles in modular distance learning delivery: input to BE-LCP to and status of BE-LCP Intervention program was tested in this study. It was found that there is significant relationship between the level of teachers' difficulties and struggles in modular distance learning delivery: input to BE-LCP to and status of BE-LCP Intervention program in terms of strategy on the learning outcomes $(r=0.630, p=0.000)$ with the degree of correlation high and on the side of Modular Learning Task with $(r=0.885, p=0.000)$. The relationship is strong and positive. This means as the teachers employ strategies, the students' outcome performance also improve even without intervention. This is because Effective instruction depends on learning experiences that are appropriately designed and facilitated by knowledgeable educators. Because every learners have different learning style so educators should design activities that include multiple modes of learning.

A significant relationship was noted between the level of teachers' difficulties and struggles in modular distance learning delivery: input to BE-LCP to and status of BE-LCP Intervention program in terms of learning plan to learning outcomes $(r=0.714, p=0.000)$ with the degree of correlation of high and Modular Learning Task with $(r=0.885, p=0.000)$ with degree of correlation of very high. The relationship is strong and positive. This means that having a learning plan as a vital component of the teaching-learning process.

A significant relationship was noted between the level of teachers' difficulties and struggles in modular distance learning delivery: input to BE-LCP to and status of BE-LCP Intervention program in terms of stakeholder's participation to learning outcomes $(r=0.715, p=0.000)$ with the degree of correlation of high and Modular Learning Task with $(r=0.799, p=0.000)$ with degree of correlation of very high. The relationship is strong and positive. This means that stakeholder's involvement as a vital component of the monitoring of the learners in the time of pandemic.

But based on the data, it shows not significant on the part of compliance and participation on the level of teachers' difficulties and struggles in modular distance learning delivery: input to BE-LCP to and status of BE-LCP Intervention program in terms strategy, learning plan and stakeholder's involvement. In stragegy, compliance got $(r=-0.030, p=0.817)$ and participation $(r=0.100, p=0.445)$ with the degree of correlation of Negligible. Learning Plan, $(r=-0.097, p=0.462)$ and participation $(r=0.021, p=0.872)$ with the degree of correlation of Negligible and Stakeholder's Involvement got $(r=-0.068, p=0.607)$ and participation $(r=0.076$, $p=0.564$ ) with the degree of correlation of Negligible. It shows that there is a need improvement on this aspect and since it is an era of transitioning and adjusting to the new normal setup of education. Parents, teachers, learners and other stakeholders are adjusting to this so on the next few years and the situation is still the same so there will be a familiarity and can think of ways on the improvement of the process. Many studies have suggested that what constitutes as "class participation" be broadened. For example, Vandrick (2000) as cited by Yu (2018) proposed that class participation should include nonverbal cues and written work by more quiet students. As it can also support the new normal setup of education at the time of pandemic which is collecting the outputs of the learners as part of their participation and compliance.

\section{CONCLUSIONS}

From the data gathered and discussed, the following conclusions were derived: The computed mean value registered Teachers Difficulties and Struggles in Modular Distance Learning Delivery: Input to BE-LCP in terms of Strategy is Highly Practiced shows that it is being practiced. At the time of pandemic in the learning continuity, teachers and parents encourage learners in the new normal. Understanding the current education setup can make a way to guide the learners in answering their activities. By giving ample time and don't give pressure can help learners to answer their task. But teachers must explain or give clear instruction for learners to easily understand the lesson. In this time of pandemic, school must open their communication to the stakeholders as they are the one who can help in the learning continuity. As they will work as one for the sake of the learners progress as they need the support to cope up with the current situation. Although in reality, learners are experiencing difficulties as they are used on the face to face instruction. But it is the start on adjusting and adapting to create ways to improve learning in the modular approach. Small or large group activities may be encouraged for both learner to participate. Teachers were evident flexible to adapt to new trend in education to cater learning As the parents participates in the effectivity of BE-LCP it will be a big impact in the next few years. Therefore, the null hypothesis was sustained.

\section{RECOMMENDATIONS}

In the light of the above findings and conclusions, the following recommendations are hereby offered:

1. Curriculum planners and educators may collaborate with individuals to create varied strategies and methods for effective teaching online learning processes.

2. School administration, parents, and other stakeholders may collaborate to assist the students and parents. 


\title{
EPRA International Journal of Research and Development (IJRD)
}

\author{
Volume: 6 | Issue: 7 | July $2021 \quad$ - Peer Reviewed Journal
}

3. For the students who still cannot access the internet, they will be given special consideration by home visitation as an example following the safety protocol.

4. Re-assess the modules and assure that all the lessons or activities are appropriate to the needs of the learners.

5. The instructions in every exercise or activities are direct and clear enough for the learners to understand what they supposed to accomplished.

6. Future researches may be undertaken to enhance the present study by considering the inclusion of other variables.

\section{REFERENCES}

1. Ambayon, C.M. (2020). "Modular-Based Approach and Students' Achievement in Literature". International Journal of Education and Literacy Studies, 8, 32-36.

2. Carreon, Joseph. (2018). “Teachers Response to Intervention for Students-at-Risk: Basis for a Proposed Action Plan." 1. 19-35. 10.13140/RG.2.2.27740.44161.

3. Cardino, J. \& Cruz, R.. (2020). "Understanding of learning styles and teaching strategies towards improving the teaching and learning of mathematics." LUMAT: International Journal on Math, Science and Technology Education. 8. 10.31129/LUMAT.8.1.1348.

4. Dejene, W. (2019). "The practice of modularized curriculum in higher education institution: Active learning and continuous assessment in focus, Cogent Education," 6:1, Research Article, DOI: 10.1080/2331186X.2019.1611052

5. Erikson, M.G., \& Erikson, M. (2018). "Learning outcomes and critical thinking - good intentions in conflict." Studies in Higher Education, 44(12), 2293-2303. 44:12, 2293-2303, DOI: 10.1080/03075079.2018.1486813

6. Gichohi, G.W (2015) International Journal of Education and Research Vol. 3 No. 2 February 2015

7. Katamei, J. \& Omwono, G. (2015). "Intervention Strategies to Improve Students' Academic Performance in Public Secondary Schools in Arid and Semi-Arid Lands in Kenya." International Journal of Social Science Studies. 3. 10.11114/ijsss.v3i4.796.

8. Roger H. \& Berwyn C. (2019) "The current emphasis on learning outcomes" International Journal of Training Research, 17:2, 93-97, DOI: 10.1080/14480220.2019.1644777

9. Mahajan, M. \& Sarjit S. Manvender Kaur. (2017). "Importance and Benefits of Learning Outcomes." IOSR Journal of Humanities and Social Science. 22. 65-67. 10.9790/0837-2203056567.

10. Mestiola, R.A., Naquita, G.P., \& Tantengco, N.S. (2018). "Enhancing Social Studies Teaching for 21st Century Learners in Secondary Education."

11. Ningsih, Soetjipto, B., \& Sumarmi (2017). "Improving the Students' Activity and Learning Outcomes on Social Sciences Subject Using Round Table and Rally Coach of Cooperative Learning Model." Journal of Education and Practice, 8, 30-37.

12. Onge, J.S., \& Eitel, K. (2017). "Increasing Active Participation and Engagement of Students in Circle Formations. Networks: An Online Journal for Teacher Research," 19, 7.

13. Tharayil, S. \& Borrego, M. \& Prince, Michael \& Nguyen, Kevin \& Shekhar, Prateek \& Finelli, Cynthia \& Waters, Ck. (2018). "Strategies to mitigate student resistance to active learning." International Journal of STEM Education. 5. 10.1186/s40594-018-0102-y.

14. Tupas, F.P., \& Linas-Laguda, M. (2020). Blended Learning - "An Approach in Philippine Basic Education Curriculum in New Normal: A Review of Current Literature." Universal Journal of Educational Research, 8, 5505-5512.1

15. Almerino, P.M., Ocampo, L., Abellana, D.P., Almerino, J.G., Mamites, I.O., Pinili, L.C., Tenerife, J.J., Sitoy, R.E., Abelgas, L.J., \& Peteros, E.D. (2020). "Evaluating the Academic Performance of K-12 Students in the Philippines: A Standardized Evaluation Approach." Education Research International, 2020, 1-8.

16. Ancho, I. V. (2020). "Old Mind-set, Values and Ethics, and Stakeholder Partnership and Accountability: Inputs to School Leadership in the New Normal." College of Graduate Studies and Teacher Education Research. Philippine Normal University 2020.

17. Jaboya, F. G. (2018), "Participation of Stakeholders in the Implementation of the Enhanced-School Based Management (SBM)"

18. Nardo,M.T.B.(2017). "Modular Instruction Enhances Learner Autonomy. Sciepub.http://pubs.sciepub.com/education/5/10/3/index.html\#:\%7E:text=The\%20use\%20of\%20modules\%20is, in $\% 20$ doing\%20their\%20individual\%20tasks.\&text=It\%20directs\%20students\%20to\%20practice\%20or\%20rehear se\%20information.,-To\%20gain\%20mastery

19. Troussas C, Krouska A, and Virvou M, "Injecting intelligence into learning management systems: the case of adaptive grainsize instruction," in Proceedings of the 2019 10th International Conference on Information, Intelligence, Systems and Aptions (IISA), IEEE, Patras, Greece, pp. 1-6, July 2019.

20. Yu, S. (2018). "Evaluating Philippine Students' Class Participation with a Token Currency System." 